This item was submitted to Loughborough's Research Repository by the author.

Items in Figshare are protected by copyright, with all rights reserved, unless otherwise indicated.

\title{
Co-operative preservation activities in the UK: findings of a research project
}

PLEASE CITE THE PUBLISHED VERSION

http://dx.doi.org/10.1108/01435129910269035

\section{PUBLISHER}

MCB University Press @ Elizabeth Gadd

VERSION

AM (Accepted Manuscript)

LICENCE

CC BY-NC-ND 4.0

\section{REPOSITORY RECORD}

Eden, Paul, and Elizabeth A. Gadd. 2019. "Co-operative Preservation Activities in the UK: Findings of a Research Project”. figshare. https://hdl.handle.net/2134/9687. 
This item was submitted to Loughborough's Institutional Repository (https://dspace.lboro.ac.uk/) by the author and is made available under the following Creative Commons Licence conditions.

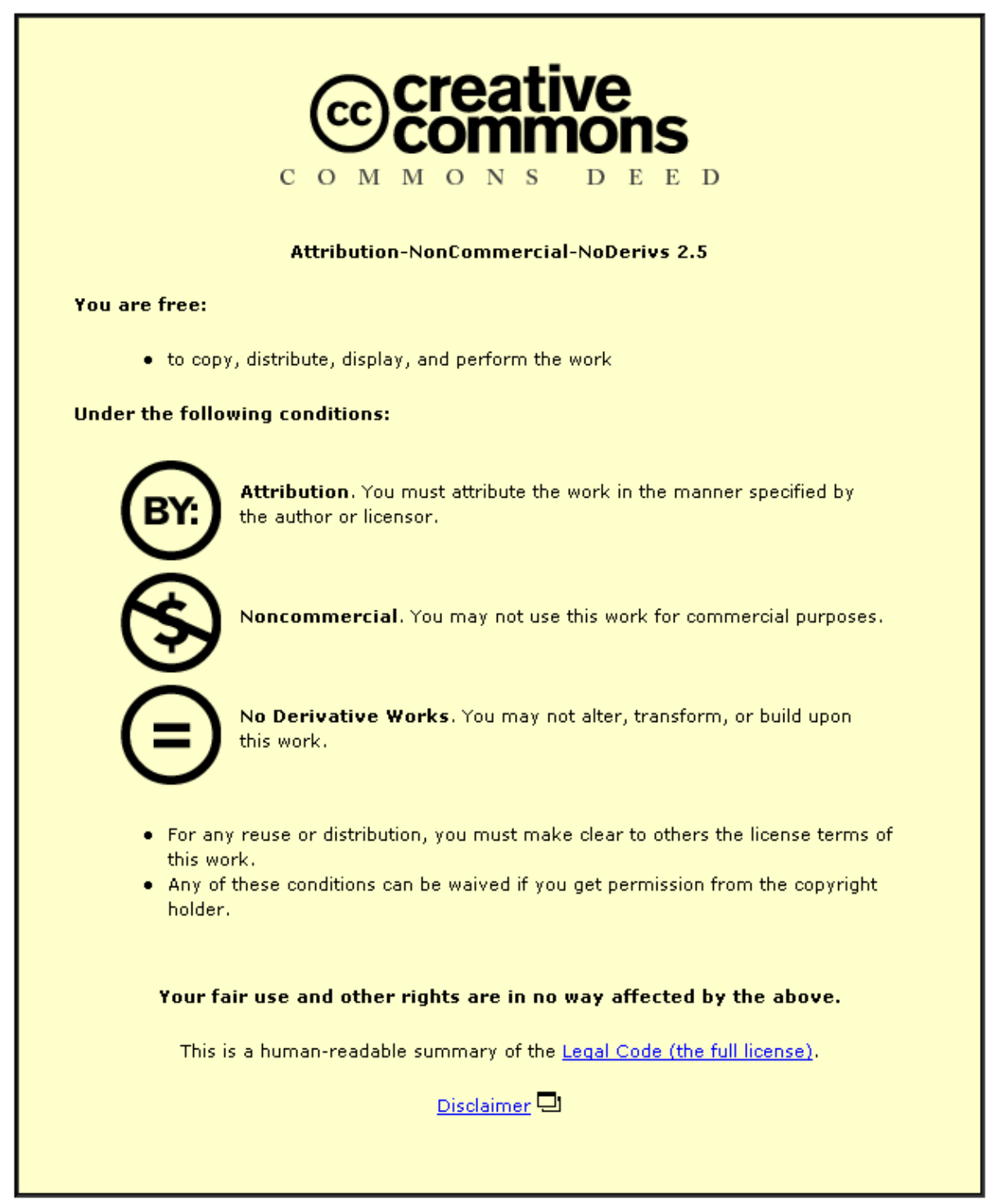

For the full text of this licence, please go to: http://creativecommons.org/licenses/by-nc-nd/2.5/ 
Co-operative preservation activities in the UK: findings of a research project Paul Eden and Elizabeth Gadd

\section{Authors}

Paul Eden is Research Fellow, Department of Information Science, Loughborough University, and Loughborough, UK.

Elizabeth Gadd is Academic Librarian, Pilkington Library, Loughborough University, Loughborough, UK.

\section{Keywords}

Archives, Co-operation, Libraries, Preservation

\section{Abstract}

Reports the findings of a BLRIC-funded research project, which set out to identify and evaluate current and recent co-operative preservation activities, and produce guidelines which will help librarians and archivists to engage in successful co-operative preservation activity.

\section{Library Management}

Volume $20 \cdot$ Number $4 \cdot 1999 \cdot$ pp. 220-227

(C) MCB University Press: ISSN 0143-5124

\section{Introduction}

Co-operation has long been recognised as "one of the best ways forward if the bulks of material in the nation's collections is to be preserved" (Ferris, 1996, p. 1). This view was supported by a British Library Research and Innovation Centre (BLRIC)funded research project carried out in 1996 which looked at preservation policies and practices in UK archives and record offices as part of wider research into national preservation policy (Feather and Eden, 1997, pp. 24-6). A second BLRIC- funded research project, begun in February 1998 in the Department of Information and Library Studies, Loughborough University, set out to build on this earlier research by identifying and evaluating current and recent co-operative preservation activities, and from this producing guidelines which will help librarians and archivists to engage in successful co-operative preservation activity.

This paper reports the initial main findings of this research. After outlining the research methodology and providing a working defini- tion of co-operative preservation activity, it describes the different types of co-operative activity identified, discusses the motivating factors behind them and looks at how they were funded. It 
then examines interviewees' and respondents' perceptions of "successful" operation, followed by a look at the main problems encountered by them during their co-operative activities. A full report of the research with guidelines will be available from the British Library Document Supply Centre.

\section{Methodology}

The research reported here is based on the findings from a literature review, requests for information, a telephone survey, face-to-face interviews and a postal questionnaire survey. The research was carried out between February and September 1998. The literature review provided an overview of co-operative preservation activity in the UK and elsewhere, thereby enabling the project team to put their own work into context. It also suggested organizations that should be contacted during the research. This information was supplemented by responses to requests for information sent to preservation-related dis- cussion lists, journals and organisations.

The telephone survey was designed to identify, and provide a preliminary evaluation of, the different types of current and recent co-operative preservation activity undertaken by the libraries and archives contacted. Questions related to:

- The different organisations involved;

- The area (s) of activity involved;

- When the activity began;

- How the activity began;

- Who is/was responsible for carrying out the activity;

- How the activity is/was funded; whether or not the activity is/was successful;

- How the activity could be improved; whether or not the interviewee knew of any other UK co-operative preservation initiatives.

The sample for the telephone survey was selected by sifting through 604 questionnaires (486 from libraries and 118 from archives) returned in response to two previous preservation surveys carried out in the Department of Information and Library Studies at Loughborough University (Eden et al., 1994; Feather and Eden, 1997). A total of 397 organisations were initially identified as candidates for the telephone survey, that is, their questionnaire responses either stated or suggested that they were involved in co-operative preservation activities. As time and other constraints made it impossible to contact so many organisations, a further sift was done by type of organisation and activity. A representative sample of 60 organisations was then selected: nine academic libraries, 13 special libraries, 18 public libraries and 20 archives. A further 29 organisations were identified from the literature search and requests for information, thus giving a total of 89 organisations for the telephone survey. Of these 89 organisations, 80 responded positively when approached. 
Whereas the telephone survey was primarily designed to find out what activities organisations were involved in, the face-to-face interviews were designed to find out why organisations chose to co-operate and how they did so successfully. Interviewees were identified during the telephone survey. Of 18 people in different organisations, 12 were interviewed, including librarians, archivists and museums personnel.

The postal questionnaire was sent to 65 co-operating organisations identified by the literature search, which although not specifically concerned with preservation might nevertheless include preservation initiatives as part of their activities. These organisations included, among others, Regional Library Systems, Standing Conference of Co-operative Library and Information Services (SCOCLIS) organisations and Library and Information Plan (LIP) co-operatives. The postal questionnaire asked whether or not the co-operative was involved in any form of preservation activity and other questions similar to those in the telephone survey. Of the 65 questionnaires sent out, 38 were returned giving a response rate of 58 per cent.

Respondents and interviewees were assured that any information they gave which was not already in the public domain would be treated in the strictest confidence. Their views and comments therefore are reported anonymously.

\section{Definitions}

Although it is likely that most librarians, archivists and other information workers would subscribe to the view that "co-operation" between them is worthwhile, it is very difficult to provide a wholly satisfactory definition of exactly what constitutes "cooperation". Previous research into library co-operation, for example, has revealed that "the understanding of the term 'co-operation' within the context of library and information services varied enormously from librarian to librarian, and from authority to authority" (Edmonds, 1986, p. 5). Other research found that "the term 'cooperation' is frequently used in a context which implies that the only really significant form of library and information service co- operation is interlending" (The Apt Partner- ship, 1995, p. 5.1). Nevertheless, a working definition of "co-operative preservation" was needed at the outset of the research reported here. Thus, while recognising inherent problems of interpretation and being aware that exceptions may always be found, for the purpose of this research "co-operative preservation" was defined as: Two or more libraries, archives and/or other organisations (including commercial) working together to preserve library and/or archive materials, and/or their information content, with the aim of facilitating appropriate access for current and potential future users.

\section{Different types of co-operative preservation activity}

The research set out to obtain a general overview of co-operative preservation activity, including which organisations tended to be involved in these activities, the 
different types of activity they were involved in and which appeared to be the most popular. The telephone survey and requests for further in- formation revealed 103 co-operative preservation activities and the postal questionnaire a further 16, giving a total of 119. Table I shows the types of organisation involved in these 119 activities broken down into different sectors (where an organisation is by nature cross- sector, for example, it is a regional library system or a LIP, it is indicated as such).

Analysis of the various activities revealed four basic types of co-operative arrangement. First, individual libraries and/or archives co-operate for particular purposes such as bulk-purchasing arrangements, but do not create a separate organisational structure to do so. Second, a group of libraries and archives, for example, in the same geographical area, establish a recognised formal body with representatives of the participating organisations meeting to discuss issues and needs of mutual interest and to plan policies and strategies. Third, there are the organisations such as regional library systems and LIPs that have preservation remit as part of a much broader range of activities. Fourth, there are the national preservation-related bodies that often work co-operatively to represent the needs of the sector(s) that they support. Far more co-operative activities were reported as taking place between organisations from different sectors than between organisations from the same sector, 83 and 36 respectively. This was perhaps to be expected given the number of cross-sector organisations and

Table 1: Organisations involved in co-operative preservation activities by sector

Sector Number of organisations

National bodies 4

National libraries and archives 8

Academic libraries $\quad 30$

Public libraries $\quad 17$

Special libraries $\quad 14$

Archives and record offices $\quad 24$

Museums and galleries 2

Cross-sector 20

National bodies involved, but it was also the result of particular expertise being offered to libraries and archives regardless of sector by, among others, conservation units and archival rescue services. 
Turning to the activities themselves, we can see from Table II that co-operative conservation was the most common activity reported. This is perhaps not surprising given that conservation demands specialist skills, requires facilities not available in most organisations and can be expensive in terms of materials. This makes cooperation for conservation not only financially attractive, but also, for many organisations, an operational necessity.

Microfilming was the second most common activity. Although this is partly a reflection of the remarkable success of NEWSPLAN, other co-operative microfilming projects were found in all sectors. This finding suggests that "Collaborative projects, whether among libraries, between libraries and commercial organisations, or entirely in the private sector, dominate the production of microfilms" (Feather et al., 1996, p. 91).

The fact that 17 organizations reported being involved in co-operative disaster management activities is significant as it highlights the diversity of skills, experience and knowledge (in areas such as risk assessment, insurance, buildings maintenance, salvage, conservation and training) required to put together an effective disaster control plan, all of which are unlikely to be found within a single organisation. It also underlines the benefits of sharing expertise and facilities in the event of a disaster, as well as the financial savings to be gained from the bulkpurchasing of emergency supplies and equipment. A good example of what can be achieved through a co-operative approach in this area is the Web-mounted disaster control plan template produced by the M25 Consortium of Higher Education libraries designed "to provide a useful model for librarians engaged in developing a library disaster control plan and fostering a disaster management culture" (<http://www.M25lib.ac.uk/M25dcp>). In addition to the template, the Web site includes guidance for librarians on disaster management issues, references to recent literature, sources of information and expertise from within the M25 Consortium and links to library plans mounted on the Web.

\section{Table II Types of co-operative preservation activity}

Activity

Number of organisations engaged in this activity

Conservation

Microfilming

Disaster management

Training

Awareness-raising

Needs assessment 


$\begin{array}{lcc}\text { Education } & 11 \\ \text { Publications } & 10 \\ \text { Shared storage } & 10 \\ \text { Standards } & 8 \\ \text { Joint purchasing } & 7 \\ \text { Providing professional advice } & 6 \\ \text { Preservation of digital data } & 6 \\ \text { Digitisation } & 5 \\ \text { Friends group } & 5 \\ \text { Acquisitions } & 4 \\ \text { Fund-raising } & 4 \\ \text { "Rescuing" materials which would otherwise be destroyed } & 4 \\ \text { Formulating strategy } & 4 \\ \text { Shared search room } & 2 \\ \text { Supplies creation } & 1\end{array}$

Co-operative training activities and education were also relatively popular, with 15 and 11 organisations participating respectively. This was mainly because they gave people the opportunity to share their skills and experience, for example, in workshops and seminars, without committing themselves to any long- term involvement in a particular enterprise. One of the simplest co-operative activities reported, awareness-raising, was practised by 14 organisations including nine of the co-operatives not specifically concerned with preservation (that is, the RLSs, SCOCUS organisations and LIPS). Indeed, this was the most common form of cooperative preservation activity in which these organisations were involved, and for three of them was the only such activity.

Although 14 organisations indicated co-operative involvement with needs assessment, in some cases this may have been synonymous with the informal exchange of information and advice or seeking professional advice. The remaining activities give an indication of the wide range of different types of co-operative activities organisations are involved in, even if some of the activities themselves are not very widespread. 


\section{Motivation}

There was seldom a single motivating factor behind the co-operative activities reported by respondents and interviewees. Nevertheless, analysis of responses to questions on how the activities began revealed recurrent themes.

Some activities were developmental and, clearly, where the outcome of an activity is intended to have implications for the library and archive professions as a whole, such as work on standards, policy and strategy (local regional and national), co-operation is essential. A Working Group of the National Preservation Office Preservation Administrators Panel, an NPO committee which "meets to discuss co-operation in preservation and the means by which this can be achieved" (<http://www.bl.uk/services/preservation/committees.htrnl>), for example, is developing a set of preservation MARC tags. If libraries and archives can be persuaded to use these tags in their bibliographic records and to share this information with the rest of the library and archive community, then individual libraries and archives will be able to base decisions on whether or not to preserve particular items and collections on a greater awareness of what is being preserved elsewhere. Hopefully, this will lead to better targeting of resources and encourage future co-operative activities.

In general terms, however, the majority of the co-operative activities reported were reactive in origin, that is, they were established as a result of a particular event or problem, or in response to changing circumstances. NEWSPLAN, for instance, a cooperative programme for pre- serving UK and Irish newspapers on archival quality microfilm involving co-operation between public libraries, the British Library, the national libraries of Scotland, Wales and Ireland and the newspaper industry was a much-needed response to the widespread problem of disintegrating newspapers in libraries throughout the UK. Furthermore, NEWSPLAN "is a good example of how co-operative work can be successfully organised at both a policy and practical level, and how solutions to local issues can make a vital contribution to national solutions" (Matheson, 1998, p. 8). Another area high- lighted as requiring a co-operative approach to try to solve identified problems was the preservation of digital and magnetic data and media. Problems relating to digital imaging and archiving, as well as the preservation of magnetic media, require co-operative solutions if, in the words of one interviewee, "digital collections are to remain accessible to everyone in the future".

In situations where library and archive materials are in a poor condition and deteriorating there is an urgent need to assess them in terms of their long-term value and take action to preserve them if required. There is an even more urgent need if material is in danger of being lost or destroyed. The Construction Industry Resource Centre Archive (CIRCA) based in Frome and managed by the Western Industrial 
Collection of Conservation Artefacts and Documentation (WICCAD) establishes cooperative arrangements with construction and other companies, government departments and individuals to save and archive libraries and records (including trade literature) they no longer wish to keep. The motivating factor for WICCAD is the fact that no other organisation is meeting the need to preserve these records and make them available to the public.

Organisational change, leading as it so often does to a re-assessment of organisational goals, funding, policies and strategies, can be a powerful motivating factor for co-operative activity. This is often the case where libraries and archives have been "''merged" following local government re-organisation. One local authority record office, for example, reported increased formal co-operative preservation arrangements with the central library as a result of them being made part of a "lifelong learning" subdivision of the Education, Arts and Libraries Department. This was said to have been facilitated by a "shift in climate" from "horrid re-billing" to one of "general co-operation".

Just as organisational changes can provide an impetus to co-operative activity, so too can personnel changes. The ((crucial factors" in moves towards close cooperation between archivists and librarians in West Sussex in the early 1990s, for example, has been ascribed to "staff changes. Within 12 months from summer 1992 both the county librarian and county archivist retired and the new post- holders quickly established a good relationship. Both were aware of the considerable benefits of co-operation" (Hayes, 1997, p. 3).

Inevitably, funding (examined in greater detail in the following section) was the primary motivating factor behind many of the reported activities. This "economic necessity" manifested itself in two main ways. First, if money was not available "inhouse" and there was a possibility of obtaining external funding to carry out a particular project, some organisations were ready to co-operate to obtain it. Second, co-operation often began in the expectation that financial savings could be made if resources and responsibilities were shared.

\section{Funding}

Seven broad categories of funding arrangements for co-operative preservation activities were identified. Categories are listed in order, from the most commonly reported to the least (although it should be noted that in many activities no additional funding was involved):

(1) External funding;

(2) payment-in-kind;

(3) Subscription;

(4) Internal funding; 
(5) joint-funding from co-operating organisations;

(6) cost-recovery; and

(7) Providing a commercial service.

Twenty-seven (23 per cent) of the 119 activities were funded with external funding, for example, from charitable bodies. This type of funding was said by many interviewees and respondents to have "freed" them to pursue the co-operative preservation activities in which they were involved. Others were in the process of putting together bids for lottery funding. One organisation had recently set up a county-wide "rescue fund" to save records which might otherwise be destroyed as a result of an endowment from the trustees of the will of a late founding vice-president.

Payment-in-kind arrangements were much more common in cross-sector activities (17) than same-sector (two), understandably so given that interviewees often spoke of the difficulties inherent in trying to get different funding mechanisms to work together.

Joint-funding occurred slightly more frequently in cross-sector activities (four) than same-sector (one). Funding by subscription was also more prevalent in cross-sector activities, for example, UPs and RLSs: 11 cross- sector activities were funded by subscription and three same-sectors. Internal funding, for example, money from the same local authority, was more common in same-sector activities, with six in samesector activities and two in cross-sector. Only cross-sector activities were funded by providing a commercial service (two) or using a cost-recovery approach (four), while in 23 activities (14 cross-sector and nine same-sector) no additional funding was involved.

In some cases the need for funding gave rise to some very imaginative solutions. One national museum, for example, received a donation of over 900 record books from motor-cycle companies that folded in the 1970s. Unfortunately, they did not realise just how many enquiries they would get in connection with these records, not only from the public, but also from the police (in connection with fraud cases). By getting motorcycle owners' clubs to part-fund a project to microfilm the records, the museum was able to archive the originals and have a much easier tool for accessing the information. In addition, because the clubs received a copy of the microfilms as payment- in-kind, the number of enquiries received by the museum fell dramatically.

\section{Perceptions of "successful" co-operation}

The telephone and postal questionnaire surveys asked only for an indication of whether or not, in the opinion of the interviewee or respondent, a particular activity was successful. The face-to-face interviews provided more detailed information on why an activity was considered successful or otherwise. Some of the most 
interesting comments related to the various ways in which success was measured, and for ease of discussion these measures can be divided into two broad categories:

(1) Meeting recognised objectives; and

(2) Additional benefits

The latter being benefits which, though actively pursued, developed out of the cooperative process itself rather than stated objectives from the outset. Each of these will be considered in turn.

Every co-operative activity should have recognised objectives, formally stated. It was therefore logical that organisations should examine the successfulness of their activities in the light of whether or not they met their objectives. If an activity was seen as being especially important, urgent or having "large scale" objectives, then it was understandably described as being "very successful", "highly successful", "a great success", etc. if its objectives were met. NEWSPLAN was often described in these terms. Where objectives were not so ambitious, activities were still considered to be "very" or "highly" successful if the objectives were not simply met, but surpassed. One questionnaire respondent, for example, wrote "the service is seen to have been highly successful and to have exceeded the objectives set in its initial business plan".

A common theme when referring to meeting specific objectives as a criterion for success was the provision of an improved service to users. A recently merged record office and library, for example, reported that increased co-operation between them "makes sense from a user's point of view" by offering increased access to collections. This is a view supported in an article describing the closer co-operation between archivists and librarians in West Sussex noted above which states that cooperation "led to a substantially improved service to local researchers" (Hayes, 1997, p. 5). Increasing use of a collection or collections was another objective often mentioned when describing successful co-operation. The chair of one friends group, for example, measured the success of a Museums Trail event by estimating that the region's museums benefited from an additional 20,000 visitors that year as a result of the interest and publicity generated by the event. A third objective frequently highlighted, as an appropriate measure of success was financial savings or gain. This included sharing expensive equipment and facilities, co-operative bulkpurchasing agreements and sharing the cost of microfilming. One archivist described a commercial microfilming arrangement as being "very lucrative" in that by allowing their partner company to film a relatively small number of documents as part of a much larger project the archive received a copy of every microfilm in the resulting series. Friends groups also described several successful fund-raising efforts. Indeed one friends group was extremely successful, raising £58,000 net in one year alone, including $£ 2,000$ from an "Adopt-an-item" scheme and $£ 7,000$ from a literature festival. 
The "additional benefits" described by respondents and interviewees included raising the profile of the organisations involved. One organisation's successes were described almost entirely in these terms, with attention being drawn to a nation-wide tour, "increased kudos" and "international interest" resulting from their work. Another organisation believed that its activities had made "a major impact at national and international level, especially given that it is a relatively small and new organisation". A second additional benefit of co-operation was said to be the development of networks and the sharing of information and expertise that subsequently resulted. This was considered especially valuable for those operating as "one-person bands" within specialist organisations where professional support is lacking. A good example of this kind of sharing of information occurred when certain members of one organisation each undertook research into a particular area of interest to the group as a whole and then reported their findings back to the group. As one participant said: "There simply wouldn't be time" for all the members of the group to pursue these areas individually.

\section{Problems encountered during co-operative preservation activities}

The main problems encountered by interviewees and respondents during their cooperative preservation activities may be grouped under three main headings:

(1) External conditions;

(2) Personalities; and

(3) Resources.

Problematic external conditions often led to feelings of frustration, and included historical factors such as the different backgrounds of participating organisations. If, for example, a co-operative group included individuals whose organisations allowed them a certain degree of autonomy, these individuals often found it difficult to accept the bureaucratic working practices of others, especially when they were slowing down the work of the group. Geographical factors were also perceived to be a potential barrier to progress, with several interviewees, including the representative of one organisation with partners in three different cities, stressing the overwhelming importance of good communication channels between them. Nevertheless, the biggest problems relating to external conditions were often the result of what might best be described as political" issues. Sometimes it was a case of "trying to please everyone" and thereby failing to achieve the best results. In one local authority, for instance, an externally-funded digitisation project led to a digitised collection of local history photographs which was described as "a bit piecemeal" because of the political necessity of photographing material from each of the townships in the borough. Similar tensions can occur where organisations have both local and cooperative objectives to meet. As one project manager said at the outset other project: "I think at this point I would flag up ... the inevitable tension between local needs and 
the strategy/policy of the consortium- applying to technical, organisational and financial implications".

Not all problems, however, are structural in origin. The importance of "personality" is such that many co-operative activities would not have started, or at least not have been so successful, had it not been for the enthusiasm or charisma of particular individuals. Unfortunately, the downside of this is that the loss of such an individual can have a destructive effect on the co-operative activities. As the member of one small group of librarians put it "[the group) has died out, partly because a member with great energy and interest retired". Indeed, one archivist saw co-operative activities as essentially organic" for the reason that they were based on personalities, and certainly the common denominator of all co-operations is that it involves people. It thus follows that compatible personalities are highly desirable if co-operative activities are to have a realistic chance of success: at the very least individuals must be able to work together effectively.

Notwithstanding the difficulties encountered by co-operating organisations as a result of unfavourable external conditions and personality issues, the most common problem cited was a lack of resources. More specifically, insufficient time, staff and money. Many interviewees and respondents drew attention to the difficulty of committing time to co-operative activities on top of their day-to- day duties, and four respondents stated that the only "improvement" they would like to make to their cooperative activities would be to increase staffing. Meanwhile, financial difficulties were almost ubiquitous. Problems such as these often meant that activities were not adequately supported or could not continue beyond a tightly budgeted project timescale. Furthermore, one respondent describing an externally-funded digital archive pointed out the disparity between the essentially long-term nature of its objectives and the short-term nature of its funding arrangements, stating that "the pilot nature and fixed period funding of the service" meant that the collections development effort was "hampered by [our] inability at present to guarantee secure and long-term preservation facilities".

Not surprisingly, given the general lack of resources, interviewees and respondents continually stressed the need to ensure the proper management of those resources that were available to them. In addition, in co-operative organisations where ideas abound it is especially important to be realistic about the resources that will need to be allocated to ensure the success of any new initiatives.

\section{Summary}

The research highlighted 22 different types of co-operative preservation activity, conservation, microfilming and disaster management, training and awareness-raising being the most common. Interestingly, far more of these co-operative activities took place between organisations from different sectors than between organisations from the same sector. This was due both to the relatively high number of cross-sector 
organisations and national bodies involved and the fact that particular services such as conservation and archival rescue were being offered to libraries and archives regardless of sector. Some activities were developmental, but the majority was reactive in origin, being established as a result of a particular event or problem, or in response to changing circumstances. Eight broad types of funding for co-operative preservation activities were identified; obtaining money from external funding bodies being the most commonly reported.

Successful co-operative activities were described both in terms of them having met recognised objectives and producing untargeted, but important, additional benefits. Problems encountered were often attributed to difficulties associated with unfavourable external conditions (including historical, geographical and political factors), the Joss of enthusiastic and charismatic people and a general lack of resources.

Such an overview of current and recent co-operative activity should prove useful in the development of guidelines for librarians and archivists wishing to initiate cooperative preservation activities or develop existing activities. It will also be of use to the NPO as it seeks to encourage and co-ordinate further co- operative activities as part of its national strategic remit, thereby helping to make the most effective and efficient use of human and technical resources at local and regional levels in support of national aims and objectives.

\section{$\underline{\text { References }}$}

The Apt Partnership (1995), The Apt Review: a Review of Library and Information Co-operation in the UK and Republic of Ireland for the Library and Information Cooperation Council (LINC), LINC, Sheffield, British Library Research and Development Report 6212.

Eden, P., Feather, J. and Matthews, G. (1994), "Preservation and library management: a reconsideration", Library Management Vol. 15 No.4, pp. 5-11.

Edmonds, D.J. (1986), Current library Co-operation and Co-ordination: an Investigation, HMSO, London, Library Information Series, No. 15.

Feather, J. and Eden, P. (1997), National Preservation Policy. Policies and Practices in Archives and Record Offices, British Library, London, British Library Research and Innovation Report 43.

Feather, J., Matthews, G. and Eden, P. (1996), Preservation Management: Policies and Practice in British Libraries, Gower, Aldershot

Ferris, V. (1996), "'To boldly go...' a new look for the National Preservation Office", Library Conservation News, Vol. 50, spring, pp. 1-2. 
Hayes, M. (1997), "Sleeping with the enemy: co-operation between archivists and librarians in West Sussex", local Studies Librarian, Vol. 16 No.1, pp. 2-5.

Matheson, A. (1998), "NEWSPLAN preserving newspaper heritage", NPO Journal, Vol. 1, pp. 8-10. 